\title{
IMAGES IN RESPIRATORY MEDICINE \\ Complications of small cell lung cancer involving the carina and treatment with a Y-stent
}

\author{
Mehdi Tahiri MD, Moishe Liberman MD PhD
}

Small cell lung cancer (SCLC) is a neuroendocrine tumour that is strongly linked with cigarette smoking and accounts for $15 \%$ to $25 \%$ of lung cancers. SCLC is discerned from non-SCLC by its rapid tumour doubling time and early dissemination. Patients with SCLC may present with varying signs and symptoms such as bloody sputum, chest pain, loss of appetite, shortness of breath, wheezing and weight loss. In the present article, we depict three different carinal complications of SCLC in three different patients.

The bronchoscopy performed on the first patient shows an extrinsic compression of the right main bronchi at the carina level. In the second patient, the image demonstrates an invasion of the carina coupled with destruction of the cartilage of the right main bronchi.


Figure 1) a Left main bronchi. b Right main bronchi. c Carina. d Y-stent recovering trachea
Finally, in the third patient, the bronchoscopy images reveal a case of bronchoesophageal fistula at the level of the carina and right main bronchus (Figures 1 to 4 ).

A Y-stent was inserted under direct vision in all three patients to palliate their symptoms.

\section{KEY LEARNING POINTS}

Carinal complications caused by SCLC are difficult problems to deal with. In our experience, these problems are often managed using silicone Y-stenting to recreate luminal anatomy and cover fistulae. 


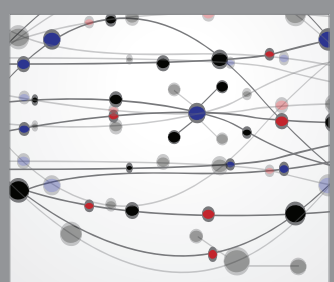

The Scientific World Journal
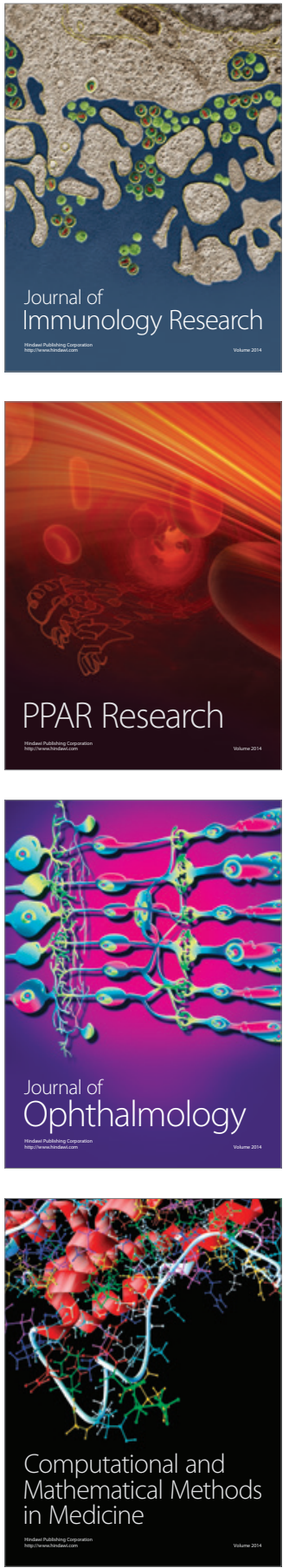

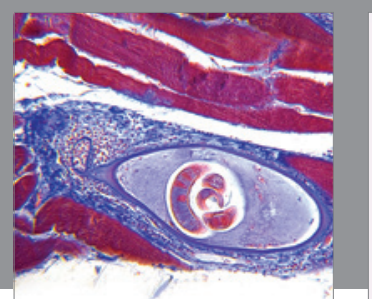

Gastroenterology Research and Practice



\section{Hindawi}

Submit your manuscripts at

http://www.hindawi.com
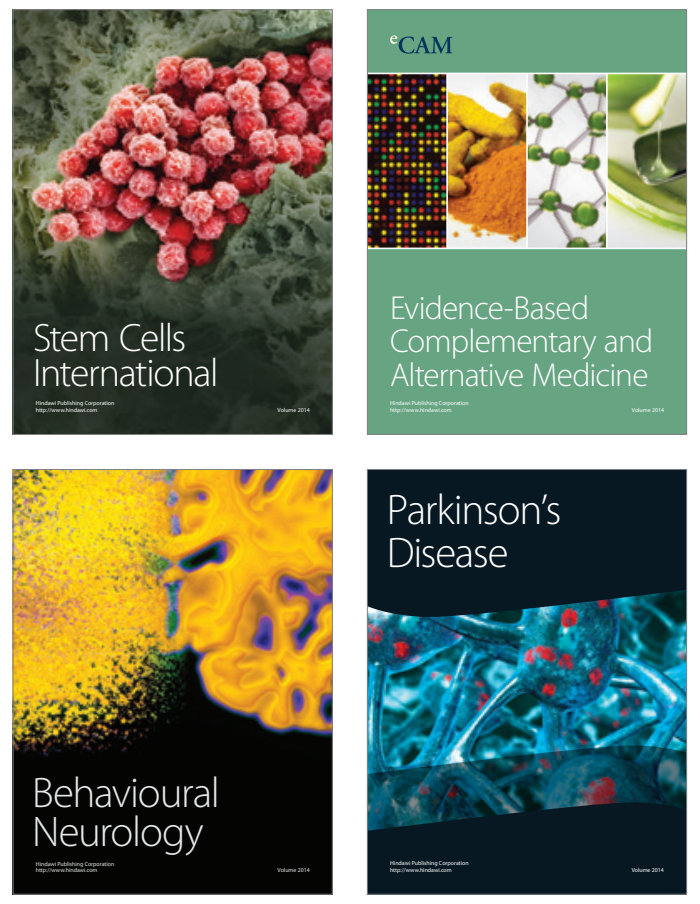
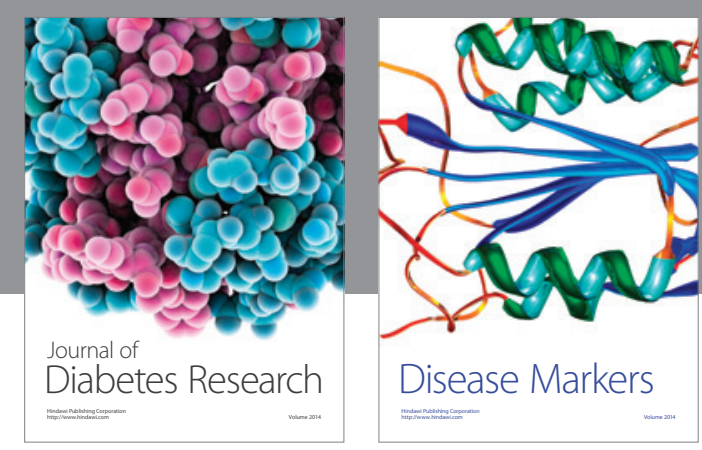

Disease Markers
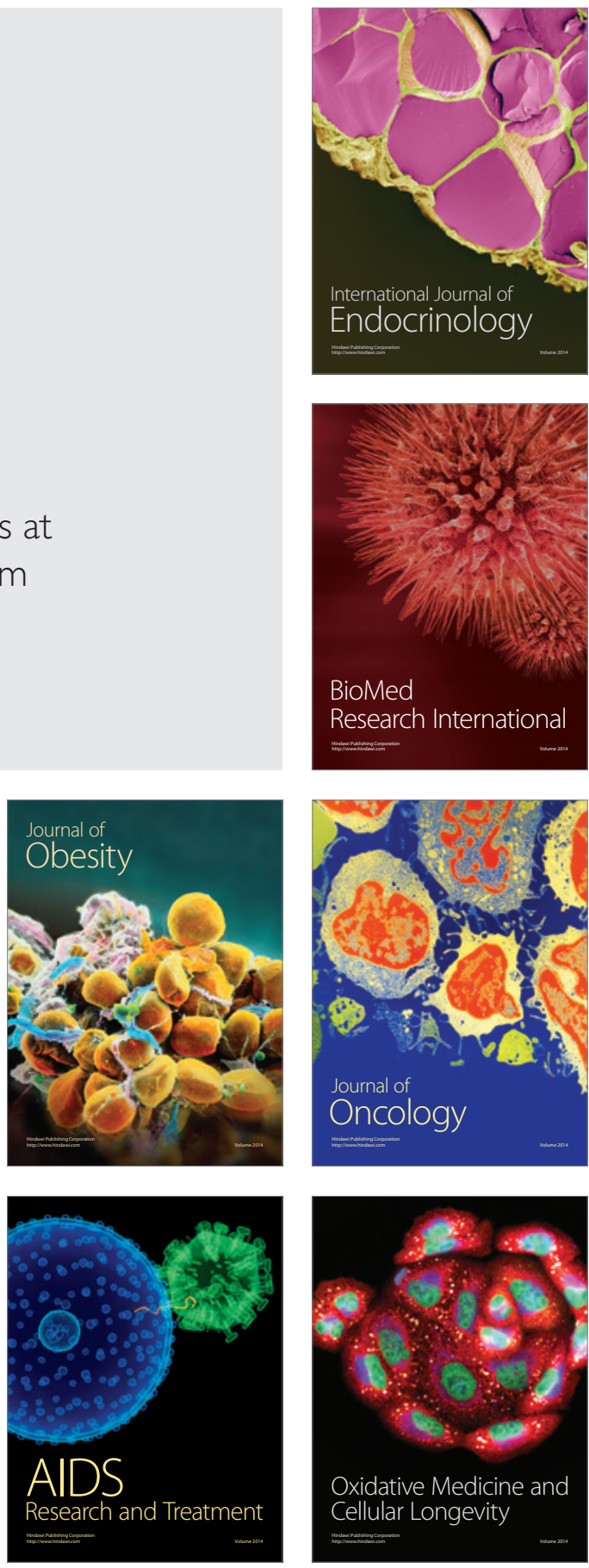